\title{
Antibiotic Resistant Pathogens in Human Environment (ATM Machine)
}

\author{
Vijayalakshmi .M ${ }^{1}$, Ranjitsingh .A .J .A $\mathrm{A}^{2}$, Uma Maheswari.$^{3}$, G. Athinarayanan ${ }^{4}$ \\ ${ }^{1,3}$ Department of Biotechnology, Manonmaniam Sundaranar University, Tirunelveli \\ ${ }^{2}$ JP College of Arts and Science, Ayikudy, Tenkasi \\ ${ }^{4}$ Department of Zoology, Sri Paramakalyani College, Alwarkurichi
}

\begin{abstract}
Nowadays antibiotic resistant pathogens become a major problem in medical history. In this present study multidrug resistant pathogens like Bacillus cereus (bacteria) and Aspergillus sp. (fungi) was isolated and identified from human environment. Swabs were taken from different area public usage environment like bus stand and ATM machine. Swabs were further inoculated in various nutrient medium for isolation. After isolation of bacterial strain it was identified using biochemical analysis, and then it was tested against 10 type of antibiotics like Methicillin, Tetracycline, Ampicillin, Ciproflaxine, Neomycin, Oflaxin, Ceftizoxime, Cefuroxime, Cefdinir, Amoxylin, for bacterial analysis. Antibiotic sensitivity was made using Kirbey Baeyer method. resistant strain was observed and DNA sequence analysis was taken. Following the same resistant fungi was also isolated and tested against antibiotics like Flucnazole, Amphotericin, Doxycycline, Metrinozole, Cycloheximide.
\end{abstract}

Keywords: Antibiotic resistance, bacterial pathogen, fungal pathogen, Antibiotic sensitivity, Bacillus cereus. Aspergillus.

\section{Introduction}

The phenomenon of bacterial drug resistance was first documented in 1951(WHO 2005). The term "resistance" is used to describe a relative insensitivity of a microbe to an antimicrobial drug as tested in vitro and compared with other isolates of the same species. In contrast, clinical failure describes failure of an appropriate therapy for a certain indication to result in a clinical response. The reason for clinical failure may be, for example, antifungal resistance, but other causes, such as an impaired immune function, poor bioavailability of the drug given, or an accelerated metabolism of the drug, are possible causes of treatment failure. (Stevens , 1999).

Microbial resistance to antibiotics, a process that has known a rapid uncontrolled growth during the last two decades in the entire world, is widely accepted today as one of the major problems of public health at the world's level (NAC 2007). It manifests itself by the seriousness of infections or the prolonged clinical symptomatology duration, increase in the number of hospitalization days, and, last but not least, by the resulting costs (Hawkey 1998). The period between the beginning of the antibiotics treatment (the 1940s) until the emergence of bacteria expressing efficient mechanisms of resistance is too short (50-60 years) to explain the coming into being and spreading of the resistance genes only through the phenomenon of spontaneous mutation (Mihaescu, 2007).

The mechanisms of resistance to antibiotics is essential in fighting a phenomenon, which is amplifying everyday due to the uncontrolled excessive and many times unjustified use of anti-microbial substances (Bogdan - Ioan et al.2009). At present it has become a matter of public health, together with the resistance of Mycobacterium tuberculosis to tuberculostatic or the spreading of the AIDS virus which not only affects the European countries but the entire globe.
The clinical profile and antibiotic antibiotic sensitivity pattern in the cases of typhoid fever. Total of 46 culture the sensitivity pattern of isolates from blood culture was recorded. Resistance to Salmonella typhi to Amoxicillin, Ciproflaxin. Ceftriaxone was showed 100\% (Mathura et al., 2005).

The period between the beginning of the antibiotics treatment (the 1940s) until the emergence of bacteria expressing efficient mechanisms of resistance is too short (50-60 years) to explain the coming into being and spreading of the resistance genes only through the phenomenon of spontaneous mutation (Mihaescu et al., 2007).

The minor alteration in the target so that it is no longer bound by the drug can cause resistance. Other reasons like alterations in membrane permeability, spontaneous mutation in DNA transfer all can contribute to the development of resistance to antimicrobial agents (Eugene et al., 1998).

The antibiotic sensitivity properties of E.Coli K12 cells were cultured under ideal growth conditions but in the presence of antibiotics as a selective environmental stress in order to select for resistance, and to determine if the data are in agreement with the theory that bacteria or other species will accumulate new phenotypic traits via development of genotypic changes that will enhance the survival of the organism (Taylor dodgen 2008). The reason for clinical failure may be, for example, antifungal resistance, but other causes, such as an impaired immune function, poor bioavailability of the drug given, or an accelerated metabolism of the drug, are possible causes of treatment failure (Stevens et al 1999). The antibiotic sensitivity of bacterial pathogens like E.Coli, Pseudomonas, Staohylococcus against selected Quinolones group of antibiotics Ciproflaxin, Oflaxin, Sparfloxacin. Here quinolones prevents the bacterial DNA from unwinding and duplicating by Topoisomerases. E.Coli, Pseudomonas are 


\section{International Journal of Science and Research (IJSR) \\ ISSN (Online): 2319-7064 \\ Index Copernicus Value (2013): 6.14 | Impact Factor (2014): 5.611}

found to be resistant to sparfloxin and Oflaxin respectively (Nakade Dhanraj 2012).

\section{Materials and Methods}

Swabs were taken from public environment like bus stand ATM machine. Swabs were inoculated in different nutrient medium Thioglycolate medium for bacteria, yeast peptone water for fungi and for the isolation, the swabs were plated in blood agar and Macconkey Agar, and colonies were separated by quadrent streaking and pure culture isolated . the isolated colonies were taken. For fungi the swabs were plated in Saboured dextrose Agar and colonies were separated. Biochemical analysis were taken in lab bacterial and fungal strain genus were identified. For further antibiotic susceptibility testing was done using disc diffusion method.( Kirby-Bauer method) Alireza Monsef,2010) 6. 10 antibiotic disc were choosen for bacteria, and 5 disc were choosen for fungi. Muller hinton agar was used for antibiotic sensitivity against bacterial pathogen .Antimycotic sensitivity Agar was used for fungal isolation. resistant multidrug pathogen was further identified and analysed by DNA sequencing.

\section{Result and Discussion}

Various studies have done about the infectious diseases but still, there is evolution of pathogenic bacteria could be identified among people. The extensively drug-resistant tuberculosis (XDR-TB), an even more severe form of drug resistant TB than multidrug-resistant TB (MDR-TB), began to appear (WHO 2005) stated that many reaccurance of tuberculosis because of streotomycin resistance bacterial strains.the mor widespread is in the patients body,the greater number of bacteria that are present and the more likely it is tha some of the pathogenic organisms contain spontaneous mutations conferring drug resistance (Gandhi et al., 2006).

The bacterial wound infection associated with Diabietic wound and testing the antibiotic susceptibility of main antibiotics. The isolated pathogens have a greater percentage as made of isolation in diabietic wounds while double pathogens were greater in non-diabietic wounds. Amoxillin was the best effective antibiotic againt common bacterial type, while aquous extracts of Myrtus communis have the variable antibacterial activity (I.e.a.alsaimary 2009). Due to growth of population, working in unhygienic condition, contamination of pathogenic form seen in the environment. However, the present study revealed emergence of drug resistant pathogen. Drug resistance pathogenic bacteria is considered to be an important factor in the mortality of the disease improved standards of public health have resulted that in a marked decline in the incidence of developing dangerous diseases in developing country. Nowadays multiplication of pathogenic bacteria in human environment is a serious problem. The solutions to the problems of antimicrobial resistance are a direct consequence of understanding the mechanisms at the basis of its emergence. From the DNA sequencing multidrug resistant isolated from ATM machine was identified as Bacillus cereus.
Table 1: Antibacterial activity of Antibiotic

\begin{tabular}{|l|c|}
\hline \multicolumn{1}{|c|}{ Antibiotic used for bacteria } & $\begin{array}{c}\text { Zone of } \\
\text { inhibition in } \\
\text { mm }\end{array}$ \\
\hline \multicolumn{1}{|c|}{ Oflaxin } & 11 \\
\hline Neomycin & 18 \\
\hline Tetracycline & 14 \\
\hline Ciprofiaxine & 20 \\
\hline $\begin{array}{l}\text { Cefdinir, Methicillin, Ampicillin, } \\
\text { Cefroxime, Amoxylin, Ceftizoxime }\end{array}$ & - \\
\hline \multicolumn{2}{|c|}{ Antul activity } \\
\hline $\begin{array}{l}\text { Fluconozole, Amphotericin, Doxycycline, } \\
\text { Metrinozole, Cycloheximide }\end{array}$ & - \\
\hline \multicolumn{2}{|c|}{} \\
\hline
\end{tabular}

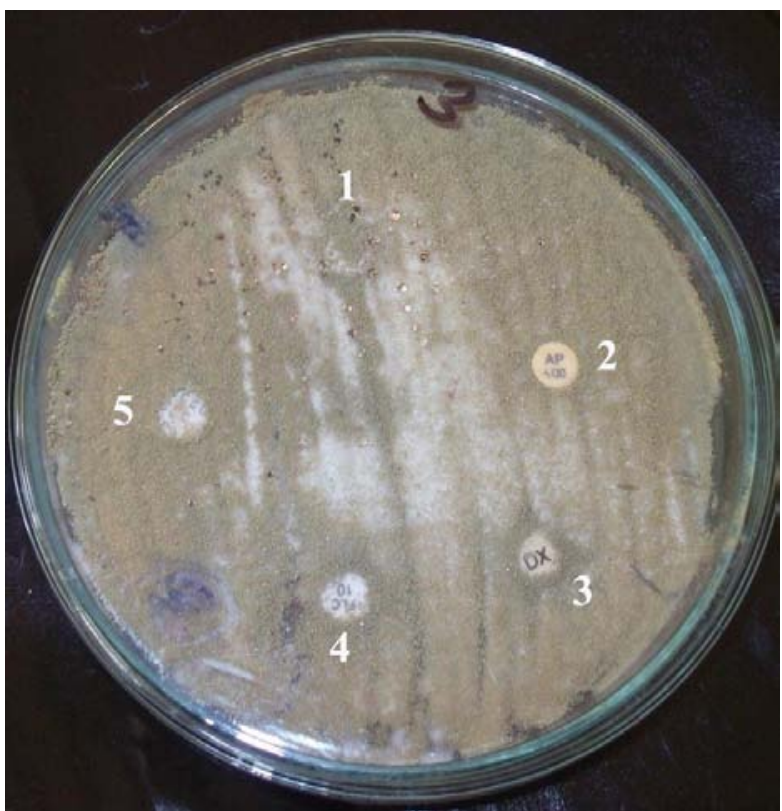

1. Fluconazole; 2.Amphotericin; 3.Doxycycline 4Metrinozole; 5-Chloroamphenical

Plate 1: Showing Anti susceptibility test for fungi

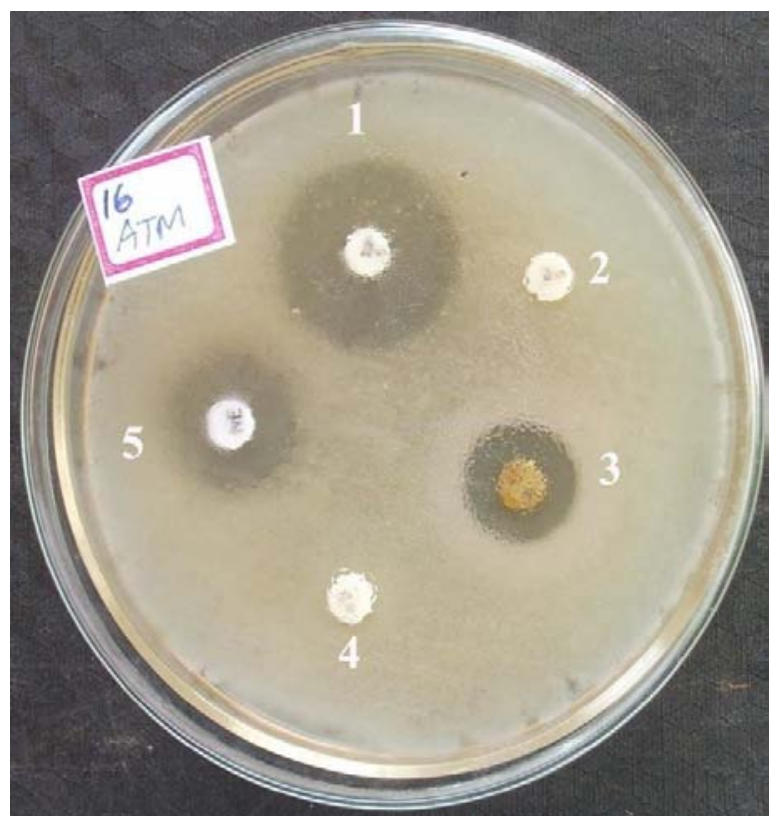

1.Ciproflaxin; 2.Ampicillin; 3.Tetracyclin 4.Cephroxime; 5.Neomycin

Plate 2: Anti susceptibility test for bacteria 


\section{International Journal of Science and Research (IJSR) \\ ISSN (Online): 2319-7064}

Index Copernicus Value (2013): 6.14 | Impact Factor (2014): 5.611

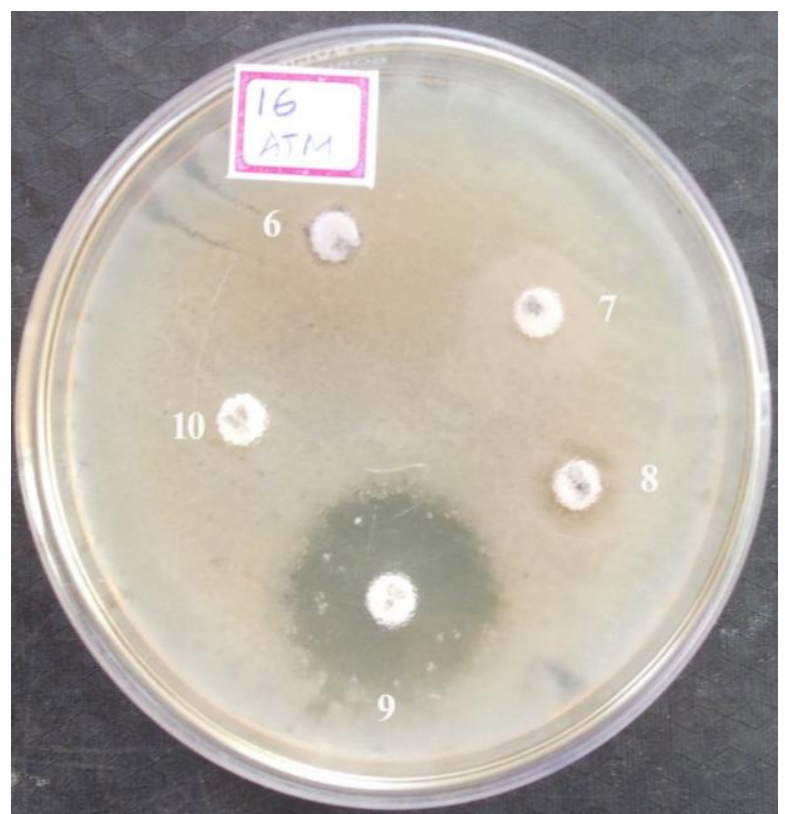

6. Ceffizoxime; 7-Amoxylin; 8.Methicilin; 9.Oflaxin; 10.Cefidinir

Plate 3: Showing Anti susceptibility test for bacteria

\section{Conclusion}

Antibiotics must be known in order to successfully fight the resistant or multi-resistant bacteria Resistance can emerge relatively quickly in the case of some mutations in target genes and there is evidence that antibiotics themselves can promote such mutations. however, resistance to most antibiotics occurs through the aegis of extremely efficient enzymes, efflux proteins and other transport systems that often are highly specialized towards specific antibiotic molecules. Such elements are the result of evolution through natural selection; this therefore implies that antibiotic resistance has a long evolutionary past .A growing body of evidence suggests that non-pathogenic environmental organisms are a reservoir of resistance genes that have the potential to be transferred to pathogens .This is because usage of antibiotics at high rate by the people. Here comparing to seasonal diseases and hereditary infectious diseases caused by pathogenic bacteria have been noticed more than other one.

\section{References}

[1] Hawkey. P.M., 1998. The origins and molecular basis of antibiotic resistance. BMJ 317:657-660

[2] Mihaescu. G., Chifiriuc. MC., Dutu. C.M., 2007. Antibiosicssi substrate chimiotera peutice anti microbiene. J Bucuresti Editura Acrdemiei Rom Ane :2007.

[3] National Association of country and city health officials statement of policy Enhancing the capacity of local health Department of monitor and prevent and control emerging multi resistant organism.Washington. CDC Report on infectious disease, 2007.

[4] Stevens. DA., Holmberg. K., 1999. Resistence to Antifungal drugs current status and clinical implications. Curr Opin Anti infect invest drugs.1:30617.
[5] World health organization Drug resistant salmonella. Fact sheet N 139; 2005.

[6] Bogdan-Ioan Coculescu. Antimicrobial resistance induced by genetic changes. Microbiology, Parasitology and Virology Laboratory - Centre of Prophylactic Medicine Bucharest, Romania. J Med Life 2009 ,Apr 15;2(2) 114-123.

[7] Mathura. K.C,, Chaudhary. D., et al., 2005. Study of clinical profile and antibiotic sensitivity pattern in culture positive typjhoid fever cases. Kathmandu University Medical Journal. vol 3,no 4.issue 12,376379.

[8] Eugene.W., Neter, Robert et al.,1998. Microbiology A human perspective $2^{\text {nd }}$ Edition McGraw- Hill Companies p516.1998.

[9] Taylor Dodgen. Senior Thesis,. E.Coli and antibiotic resistance to tetracycline antibiotics. Liberty University,Spring.2008.

[10] Alireza Monsef. Fatemeh Eghbalian. 2010. Antibiotic sensitivity pattern of common bacterial pathogens NICU and neonatal ward in Hamedan province of Iran. Vol.2, No.6, 625-629.

[11] World Health Organization Drug resistant Salmonella. Fact sheet. 2005. 139.

[12] Gandhi NR. Moll. A., Strum. AW., Pawinski. R., 2006. Extensively drug resistant tuberculosis as a cause of death in patients co-infected with HIV in a rural area of South Africa. Lancet.368: 1575-1580.

[13] I.e.a.Alsaimary. 2009. Bacterial Wound Infections in Diabetic patients and their Therapeutic implications. The Journal of Microbiology. vol 7 no.2. 